\title{
Neurodevelopmental screen in the school entrant medical examination as a predictor of coordination and communication difficulties
}

\author{
C R HAINES, J B BROWN, E B GRANTHAM, V S RAJAGOPALAN, AND \\ P V SUTCLIFFE
}

Child and School Health Service, Peterborough Health Authority

SUMmARY A neurodevelopmental screen in the medical examination of 3750 school entrants with a mean age of 5 years 4 months was validated as a predictor of coordination and communication difficulties. Class teachers of 6,7 , and 8 year olds completed a questionnaire about motor and communication success and difficulty in school activities. Below average ratings on the neurodevelopmental screen were associated with later problems in school activities. The findings, reported to all head teachers, suggest some approaches to intervention in school. The neurodevelopmental screen contributes to early assessment of special education needs of clumsy children.

Medical recognition of problems of clumsy children developed in the 1960 s. These children, usually aged 8 years or more and receiving junior age education, presented at hospital clinics with coordination and behaviour problems. Diagnosis of school problems in hospital clinics may create difficulties. A comprehensive review supported an extended range of clinical and hospital based assessment and treatments. ${ }^{1}$

A neurodevelopmental screen was developed during a large scale medical and educational survey, ${ }^{2}$ was discussed ${ }^{3}$ and reported, ${ }^{4}$ and continues in use. ${ }^{5}$ Neurodevelopmental tests are also available for teachers to screen children educationally 'at risk' ${ }^{6}$ The need to follow up early medical recognition of clumsy children with educational treatment was emphasised. ${ }^{78}$ The 1981 Education Act drew attention to perceptual, motor, and communication skills: it requires teachers, educational psychologists, and school doctors each to describe a child's functional strengths and weaknesses and to involve parents in early informal assessment closely related to education. ${ }^{9} \mathrm{~A}$ survey of 201 health authorities showed that in April 1984 $141(70 \%)$ used a neurodevelopmental screen in the medical examination for school entrants.

Preschool medical assessment of neurological development is also recommended. ${ }^{10} \mathrm{~A}$ family doctor surveillance scheme refers to preschool neurodevelopmental checks. ${ }^{11}$ The recent survey also showed that $18(9 \%)$ health authorities gave children a medical before school entry rather tha afterwards.

In 1976 a pilot neurodevelopmental screen called an activity chart was integrated into a longer medical examination for school entrants in all schools within a health district. Each school also now had a nominated doctor whereas rapid routine medical inspections had previously been allocated to any available doctor. The activity chart had been in use for five years before the education authority was approached to support its evaluation as a predictor of coordination and communication difficulties in school with a view to planning early education intervention.

\section{Method}

Activity chart. Items were copying shapes (circle, plus sign, square, triangle, and diamond), testing both hands for thumb and fingertip touch and both legs for hopping, bouncing, and catching a ball, picking up coins ( $2 p$ pieces) simultaneously with both hands, copying a tapped rhythm, and repetition of sentences for a count of speech sound errors. Ball kicking was an enjoyable extra activity. Guidelines were given for rating items. Speech sound sentences and the chart as a whole were rated subjectively. Items not performed were recorded as refusals. Doctors could record presence of parents, follow up 
arrangements, and referral to speech therapy and to medical opinion in tick boxes.

The children evaluated were born between 1 September 1973 and 31 August 1975. A retrospective search of medical records produced charts completed by 11 doctors during 10 terms between January 1978 and April 1981. The children were aged 4,5 , and 6 years with a mean of 5 years 4 months. The wide age range was due to schools admitting entrants at different ages and uneven levels in medical staffing. The chart has not been tested for consistency because an exact repeat would include a practice effect. It is too sparse and the items too specific to test reliability by split or alternative forms. Consistency between doctors has not been tested either. Discussion and video film reduced variation in administration. It was anticipated that during evaluation the chart might reveal variation related to doctors' professional backgrounds, which for some differed from community paediatrics and educational medicine.

School questionnaire. During June and July of the summer term 1982 teachers completed a questionnaire for children with the defined dates of birth, then aged 6-7 and in the final year of infant education or 7-8 and in the first year of junior education. Of the 96 schools, each with a head teacher, 50 had both infant and junior pupils, 23 had only infant pupils, and 23 had only junior pupils. Teachers marked a horizontal analog line to answer questions about children's achievements in familiar activities in and around the classroom. They also used tick boxes to rate the children's handwriting in a sentence copied from the blackboard. Afterwards, 6+ reading survey scores were added to completed questionnaires. A condition of evaluation was that neither individual schools nor classes were identified.

Data for analysis. Doctors' rating on 4218 charts were coded on a five point scale: 1 above average, 2 slightly above average, 3 average, 4 slightly below average, and 5 below average. The amount of follow up arrangements and the number of items refused were coded. Tick boxes for referral to speech therapy were excluded because the level of service varied at that time. No boxes referring to medical opinion were ticked.

Overall, 4677 (91\%) questionnaires were completed, within which $99.3 \%$ of the questions were answered. Four of the 96 schools did not complete questionnaires. Teachers answered questions about frequency of either failure in achievement-for example, pupil is unreliable in carrying messagesor success in achievement-for example, pupil retains verbal instructions for a complex task. Teachers' analog marks were converted to a five point scale: 1 invariably, 2 above average, 3 average, 4 below average, and 5 not at all. In the analysis children with problems were those scoring 1 and 2 on questions about failure in achievement and those scoring 4 and 5 on questions about success in achievement - that is, those with either small or large numerical scores. Tick boxes for rating the handwriting samples were coded on a five point scale: 1 very good, 2 above average, 3 average, 4 below average, 5 extremely limited. Banded $6+$ reading scores were coded 1 for $\leqslant 75,2$ for $76-90,3$ for 91-110, 4 for $111-125$, and 5 for $\geqslant 126$.

Data for 3750 children with both charts and questionnaires were analysed to test the activity chart as a predictor. In addition, all 4677 school questionnaires were analysed, to estimate the impact that problems had on the school day, as were all 4211 activity charts, to show facets of the chart as a measure irrespective of any predictive validity. The methods of statistical analysis included $t$ test, one way analysis of variance, non-parametric analysis, linear regression, and analysis of contingency tables. No data were analysed for 60 children with physical handicaps. Laterality was recorded for a separate study.

\section{Results}

Activity chart as a predictor. Mean scores of separate school questions were tested against the children with chart ratings average or above and below average. There were highly significant associations between below average chart ratings and school problem scores for gross and fine motor, writing, and communication activities. All activity chart items except ball kicking predicted school difficulties (Table 1 ). Of children with $6+$ reading scores of $\geqslant 126$, school questions about fine motor and writing problems were predicted by the activity chart items thumb and fingertip touch and shape copying (Table 2). Among these very good readers there were no significant associations between fine motor skills and picking up $2 p$ pieces nor between gross motor skills and chart hopping.

Problems in school. The school questionnaire showed that teachers observed significantly more problems in curriculum activities among older children (Table 3). In contrast there were no significant differences related to age in the rating of the sentence children copied from the blackboard. One question identified 507 children invariably last in the cloakroom, of whom 179 (35\%) had motor problems. Among the 4160 children who left promptly 
Table 1 Comparison of mean scores of school questions for children $(n=3750)$ with activity chart item ratings of average $\overline{\overline{0}}$ and above and all below average

\begin{tabular}{|c|c|c|c|c|c|c|c|c|c|}
\hline \multirow{2}{*}{$\begin{array}{l}\text { School questions } \\
\text { (Problem scores are either small }(S) \text { or } \\
\text { large }(L))\end{array}$} & \multicolumn{3}{|c|}{ Mean school question scores } & \multicolumn{3}{|c|}{ Mean school question scores } & \multicolumn{3}{|c|}{ Mean school question scores } \\
\hline & Average & Belor & $v$ average & Average & Belor & average & Average & Below & average \\
\hline Gross motor activity: & \multicolumn{3}{|c|}{ Item: ball bounce and catch } & \multicolumn{3}{|c|}{ Item: hopping } & \multicolumn{3}{|c|}{ Item: ball kicking } \\
\hline Bumps into things (S) & $3 \cdot 82$ & $3 \cdot 57$ & $* * * *$ & 3.77 & $3 \cdot 27$ & $* * * *$ & 3.75 & 3.46 & $*$ \\
\hline Awkward in games $(\mathbf{S})$ & $3 \cdot 76$ & 3.39 & $* * * *$ & 3.68 & $3 \cdot 12$ & $* * * *$ & 3.65 & $3 \cdot 36$ & $*$ \\
\hline Maintains balance in physical training (L) & $2 \cdot 10$ & $2 \cdot 41$ & $* * * *$ & $2 \cdot 16$ & $2 \cdot 68$ & $* * * *$ & $2 \cdot 19$ & $2 \cdot 36$ & \\
\hline Has spring in physical training (L) & $2 \cdot 25$ & $2 \cdot 52$ & $* * * *$ & $2 \cdot 29$ & $2 \cdot 78$ & $* * * *$ & $2 \cdot 33$ & $2 \cdot 44$ & \\
\hline Accurate responses in physical training $(\mathrm{L})$ & $2 \cdot 33$ & $2 \cdot 58$ & $* * * *$ & $2 \cdot 36$ & $2 \cdot 98$ & $* * * *$ & $2 \cdot 40$ & $2 \cdot 64$ & $*$ \\
\hline \multirow{3}{*}{$\begin{array}{l}\text { Fine motor activity. } \\
\text { Neat crayoning inside a shape (L) } \\
\text { Neat with scissors (L) }\end{array}$} & \multicolumn{3}{|c|}{ Item: thumb and fingertip touch } & \multicolumn{6}{|c|}{ Item: picking up coins quickly } \\
\hline & $2 \cdot 23$ & $2 \cdot 55$ & $* * * *$ & $2 \cdot 22$ & $2 \cdot 45$ & $* * * *$ & & & \\
\hline & $2 \cdot 37$ & $2 \cdot 74$ & $* * * *$ & $2 \cdot 35$ & $2 \cdot 64$ & $* * * *$ & & & \\
\hline Writing: & \multicolumn{9}{|c|}{ Item: shape copying } \\
\hline Omission of letters and words (S) & $2 \cdot 76$ & $2 \cdot 43$ & **** & & & & & & \\
\hline Progress in writing skills (L) & $2 \cdot 34$ & 3.00 & $* * * *$ & & & & & & \\
\hline Acceptable level in written work (L) & 2.44 & 3.20 & $* * * *$ & & & & & & \\
\hline & \multicolumn{9}{|c|}{ Item: rhythm tapping } \\
\hline Omission of letters and words (S) & $3 \cdot 32$ & 3.01 & $* * * *$ & & & & & & \\
\hline Communication activities: & \multicolumn{3}{|c|}{ Item: rhythm tapping } & \multicolumn{3}{|c|}{ Item: sound sentence errors } & \multicolumn{3}{|c|}{ Item: sound sentences summary } \\
\hline Uses limited vocabulary (S) & $3 \cdot 44$ & 2.91 & $* * *$ & $3 \cdot 19$ & $2 \cdot 91$ & & $3 \cdot 21$ & $2 \cdot 81$ & $*$ \\
\hline Unreliable message carrying (S) & 3.75 & $3 \cdot 23$ & $* * *$ & 3.47 & $3 \cdot 29$ & & $3 \cdot 52$ & $3 \cdot 15$ & $*$ \\
\hline Words clearly articulated (L) & 2.75 & 2.96 & & 2.63 & $3 \cdot 29$ & $* * * *$ & $2 \cdot 63$ & $3 \cdot 40$ & $* * * *$ \\
\hline Orderly narrative in speaking (L) & 2.41 & $2 \cdot 78$ & $* *$ & $2 \cdot 50$ & $2 \cdot 89$ & $* *$ & $2 \cdot 51$ & $2 \cdot 96$ & ** \\
\hline Can keep steady beat (L) & $2 \cdot 40$ & $2 \cdot 78$ & ** & $2 \cdot 51$ & $2 \cdot 88$ & $* *$ & $2 \cdot 51$ & $2 \cdot 94$ & $* * *$ \\
\hline Accurate copy of rhythm (L) & $2 \cdot 48$ & $2 \cdot 84$ & $* *$ & 2.57 & 2.95 & $* *$ & $2 \cdot 56$ & $3 \cdot 05$ & $* * * *$ \\
\hline
\end{tabular}

"p<0.05; " $p<0.01 ; * * p<0.001 ; * * * p=0.0001$.

Table 2 Comparison of scores of school questions with activity chart item ratings of average and above and all below average for children with $6+$ reading scores $76-125$ and $126+(n=3750)$

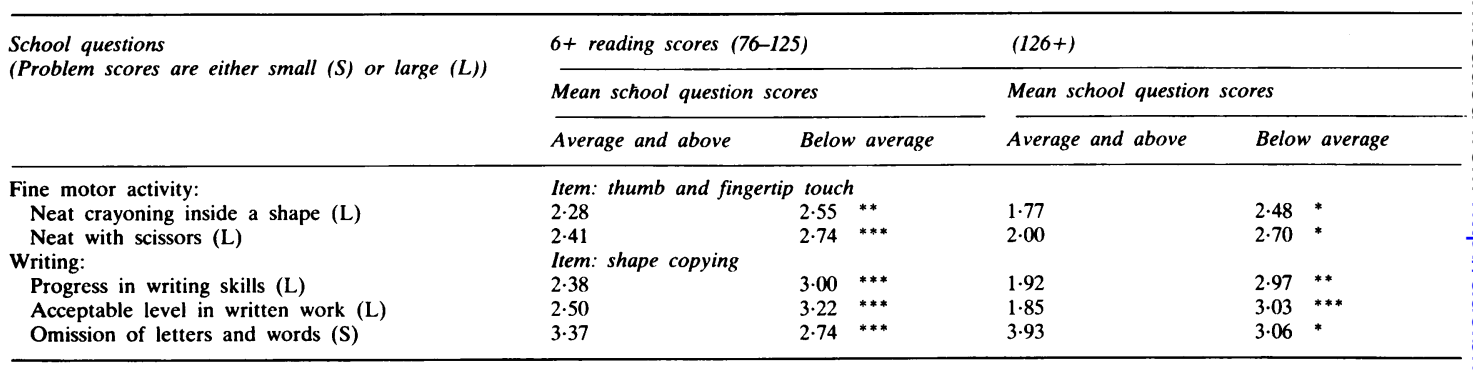

${ }^{*} \mathrm{p}<0.01 ;{ }^{* *} \mathrm{p}<0.001 ;{ }^{* * *} \mathrm{p}=0.0001$.

Table 3 Comparison of mean scores on school questions with age of children ( $n=4677)$

\begin{tabular}{|c|c|c|c|}
\hline $\begin{array}{l}\text { School questions } \\
\text { (On all questions size of score relates } \\
\text { directly to problem) }\end{array}$ & $\begin{array}{l}6-7 \text { year olds in } \\
\text { infant school }\end{array}$ & $\begin{array}{l}6-7 \text { and } 7-8 \text { year olds } \\
\text { in schools with infant } \\
\text { and junior pupils }\end{array}$ & $\begin{array}{l}7-8 \text { year olds in } \\
\text { junior schools }\end{array}$ \\
\hline $\begin{array}{l}\text { Maintains balance in physical training } \\
\text { Has spring in physical training } \\
\text { Accurate responses in physical training } \\
\text { Correct dressing and undressing } \\
\text { Neat crayoning inside a shape } \\
\text { Neat with scissors } \\
\text { Progress in writing skills } \\
\text { Acceptable level in written work }\end{array}$ & $\begin{array}{l}2 \cdot 15 \\
2 \cdot 27 \\
2 \cdot 37 \\
1 \cdot 70 \\
2 \cdot 15 \\
2 \cdot 31 \\
2 \cdot 33 \\
2 \cdot 47\end{array}$ & $\begin{array}{l}2 \cdot 25 \\
2 \cdot 37 \\
2 \cdot 37 \\
1.80 \\
2 \cdot 25 \\
2.38 \\
2.40 \\
2 \cdot 50\end{array}$ & $\begin{array}{ll}2 \cdot 27 & * * \\
2 \cdot 44 & * * \\
2.48 & * \\
1.81 & * * \\
2.44 & * * * * \\
2.58 & * * * * \\
2.52 & * * * \\
2.61 & *\end{array}$ \\
\hline
\end{tabular}


Table 4 Activity chart items and refusals

\begin{tabular}{lcl}
\hline Items & No $(\%)$ of refusals & $(n)$ \\
\hline Shape copying & $26(0 \cdot 66)$ & $(3924)$ \\
Ball kicking & $28(0.98)$ & $(2844)$ \\
Rhythm tapping & $29(1 \cdot 04)$ & $(2791)$ \\
Picking up coins & $35(1.24)$ & $(2820)$ \\
Ball bounce and catch & $69(1 \cdot 76)$ & $(3922)$ \\
Thumb and fingertip touch & $76(1.91)$ & $(3972)$ \\
Speech sound sentences & $105(2.93)$ & $(3584)$ \\
Hopping & $125(3.15)$ & $(3970)$ \\
\hline
\end{tabular}

only $643(15 \%)$ had motor problems. Similarly, 45 $(9 \%)$ of those last in the cloakroom had expressive speech problems compared with $188(4 \cdot 5 \%)$ who were not last.

Activity chart as a measure. Analysis of summary ratings of all activity charts showed that the 387 children rated below average were significantly the youngest with a mean age of 5 years 15 weeks. The 3416 children rated average and above had a mean age of 5 years 23 weeks. The 284 children with the intermediate rating of slightly below average were the oldest with a mean age of 5 years 30 weeks $(p=0 \cdot 0001)$. Doctors experienced in community paediatrics completed 3264 charts and rated 646 $(20 \%)$ below average on summary. Doctors with other backgrounds rated $21(2 \%)$ below average in 950 charts. Follow up arrangements were recorded for $517(12 \%)$ children in 4214 charts. Thirty six $(7 \%)$ of these involved discussion with parents and teaching staff, and $17(3 \%)$ combined discussion with arrangements for re-examination and had a copy of the chart sent to the educational psychologist.

In 4209 activity charts 149 (3.5\%) children did not do one or more items. Presence of parents, who attended $91 \%$ of medicals, did not significantly increase refusals. Refusals were related to age: 56 $(8 \%)$ four year olds $(n=729), 92(3 \%)$ five year olds $(n=2914)$, and one six year old $(n=566)$ refused. The refusal rate of items differed (Table 4).

\section{Discussion}

The activity chart, included in medical examination for school entrants now for nine years, seems acceptable to children, parents, and schools. It was introduced in the knowledge that there is no evidence that clinic based treatments or training programmes to develop splinter skills have an effect on learning. Experience suggests that children are not encouraged if their school failure is investigated medically. There is agreement, however, that clumsy children benefit from sympathetic treatment by parents and teachers when they are older ${ }^{1}$ and at school entry. ${ }^{3}$ This will also be the advice given by doctors in their schools when discussing children who show difficulty on the activity chart. Its evaluation now shows that a sympathetic attitude towards clumsy school entrants seems not to prevent later coordination and communication difficulties and suggests some ideas about practical intervention in school. At the suggestion of the education authority all head teachers received a report essentially similar to this one.

The heightened expectation among junior class teachers for achievement in school activities is in keeping with clumsy children reaching hospital clinics at this later age. It reflects the generally greater demands made of children on transfer from infant to junior teaching ${ }^{12}$ and in particular the more critical attitude of specialist teachers in physical education in junior schools. Younger children presumably have similar but unrecognised coordination problems. Infant class teachers, physical education teacher, physiotherapist, school doctor, and nurse might usefully compare observations about children going round an obstacle course. As the chart predicts difficulties with fine motor coordination even among very good readers perhaps infant class teachers, whose rating on the handwriting sample does not differ from junior class teachers, should monitor early writing skills more closely. Further analysis could explore the effect of clumsiness on early handwriting, described as a comparatively under-researched field. ${ }^{13}$ Children invariably last in the cloakroom are disadvantaged by missing the introduction to the next event. Reversal of traditional exhortation and new encouragement to slow down and talk more may help a clumsy child to treat a dyspraxic motor and speech problem by talking through the task of organising clothes.

Acceptability of the activity chart within school is probably enhanced by its modest clinical scope. The $6+$ reading score is in keeping with this. Had evaluation extended to prediction of learning problems it would have been necessary to include psychometry. Overinterpretation of the chart as a kind of differential diagnosis of psychoneurological learning difficulties may unintentionally be invited because single items test distinct functions. There is interest in the child who has, say, serious difficulty with auditory memory and rhythm tapping, but excels in visuomotor skills of shape copying. Overinterpretation may also be encouraged by the need now to assess both strengths and weaknesses. ${ }^{9}$ The evaluation, however, concentrates on problems, the focus of clinical interest when the chart was introduced in 1976.

Deficits in communication skills predicted by the 
chart are the findings of greatest significance for learning. Studies on clumsy children give comparatively little weight to language problems and speech dyspraxia. Further study lies properly within the province of speech therapists, who should also provide a broader consultative function across the general population of children. ${ }^{8}$

School doctors are advised to study the subject of suitable items for neurodevelopmental screen. ${ }^{3} \mathrm{Re}$ ported screens depend on personally devised scoring systems. ${ }^{4} 1415$ The chosen activity items came from standard scales and were identical with neurological tests used to examine clumsy children. ${ }^{16}$ Items for 5 year olds were adapted to criterion referencing to encompass abilities of 4 and 6 year olds without using scored pass/fail results on items for each separate year. Criterion referencing also reduced the competitive element of best or quickest performance, of limited appeal to young children, although revealing clinically. The only timed item, picking up $2 p$ pieces, was a good predictor and one of the least refused, but was unpopular with doctors. Digit repetition as a test of short term memory and sequencing was rejected from the start because failure, appearing to be related to numeracy skills, is upsetting for child and parent. The preferred rhythm tapping is of interest both as an innovation and a good predictor. Tapping patterns described as suitable for 7-18 year olds have recently become available. ${ }^{17}$

The selected items formed a short, apparently non-clinical screen that depends on observation of variation among normal children, long described as a necessary ability of school doctors. ${ }^{18}$ These characteristics seem sufficient to explain why doctors experienced and secure in clinical work in school were more likely to find below average children on the activity chart than those with other backgrounds. Recognised training in community paediatrics and education medicine is awaited.

Activity chart refusals require further study. The low rate of items not done $(3 \cdot 5 \%)$ suggests that the activity chart was acceptable to children. These refusals do not differentiate between children who completed items at a later session after refusing when their parents were present, nor do they include children who capitulated after refusing earlier in the session. Inability, rather than unwillingness, probably explains the preponderance of refusals among 4 year olds, and that hopping was the most refused item. Four year olds who do not cooperate invite further analysis. ${ }^{19}$

The youngest children were significantly more likely to be rated below average on the activity chart, probably owing to immaturity. The youngest age at which response to tests of indoor motor tasks is reliable is $4 \frac{1}{2}$ years. An additional problem is a high ceiling for motor skills at this age, so that the exceptionally agile child may increase the impression of immaturity in others. When parents watch a? 4 year old having difficulty with a compact display of $\frac{\overline{\bar{N}}}{\mathrm{~N}}$ activity items, reassuring them that the child is developmentally satisfactory may be difficult. De- $\propto$ spite variable maturity of coordination of the 4 year olds, the activity chart now provides a profile relevant to education progress. An earlier preschool $\stackrel{\circ}{\circ}$ check $^{11}$ is unlikely to yield useful information about $\vec{\omega}$ coordination.

It was thought older children would probably be rated above average by doctors. Instead, older, more mature children were rated as slightly below aver-? age. This confirms early observations using the chart $\vec{N}$ that 'the bright but clumsy child' needed a rating $\vec{A}$ between average and below average. Video film is being examined for different qualities in response to $O$ chart items that might be characteristic of develop- $\rightarrow$ mental or neurological deficits. There is interest in

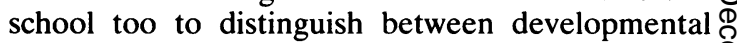
and neurological responses in the chart. Where $\stackrel{\mathscr{\Phi}}{3}$ there is any implication of brain damage, however slight, teachers may seem to consider that educa- $\stackrel{\infty}{-}$ tional help is less effective and even possib $\overrightarrow{0}$ harmful compared with remediation of developme on tal retardation. This may well involve the doctor cautious discussion about medical background such as low birthweight. ${ }^{20}$ Parents may enlarge such a discussion by observing that another member of the family is also clumsy. A familial basis for clumsiness $\frac{\circ}{0}$ is overlooked in reports. Whether planned interven- $\stackrel{2}{\Rightarrow}$ tion in school is for neurological or developmental 윽 problems we must also allow for the incalculable factor of the clumsy child's unpredictable resources for compensation.

The evaluation received a grant from the East Anglian Regional $?$ Health Authority and is indebted for analysis of data to $\mathrm{Dr} R$ Hanka and Dr P Pynsent (CRH). We are also indebted to $\mathrm{Mr} \mathrm{N}$. Coulson and colleagues, and to area education officers and teachers in Peterborough and Huntingdon, Cambridgeshire Educa- 3 tion Authority. Our thanks to Mrs C A M White and Mrs D J Mance for speech sound sentences, to Mr M Patterson for rhythm tapping patterns, our colleagues no longer in post, and in particular to Mrs S E Thompson, project assistant.

\section{References}

1 Gordon N, McKinlay I. Helping clumsy children. Edinburgh: Churchill Livingstone, 1980.

2 Rutter M, Tizard J, Whitmore K. Education, health and behaviour. London: Longman, 1970.

3 Department of Education and Science. The health of the schoole child 1966-1968. London: HMSO, 1969.

4 Bax M, Whitmore K. Neurodevelopmental screening in the school entrant medical examination. Lancet 1973;ii:368-70.

5 Whitmore K. Health services in schools-a new look. London: Spastics International Medical Publications 1985. 
${ }^{6}$ Wolfendale S, Bryans T. Identification of learning difficulties. Stafford: National Association for Remedial Education, 1979.

${ }^{7} A$ language for life. Report of the Committee of Inquiry appointed by the Secretary of State for Education and Science under the Chairmanship of Sir Alan Bullock FBA. London: HMSO, 1975.

${ }^{8}$ Wedell K, Raybound EC, eds. The early identification of educationally 'at risk' children. Educational review 1976. Occasional publications number six. University of Birmingham.

${ }^{9}$ Department of Education and Science, and Department of Health and Social Security. Assessments and statements of special educational needs. Circular $1 / 83$ and Health Circular $\mathrm{HC}(83) 31983$.

10 Fit for the future. Report of the Committee on Child Health Services. London: HMSO, 1976.

$"$ Handbook of preventive care for pre-school children. The General Medical Services Committee of the British Medical Association and the Royal College of General Practitioners, 1984.

12 Bennett N, Desforges C, Cockburn A, Wilkinson B. The quality of pupil learning experiences. London: Lawrence Erlbaum Associates, 1984.

${ }^{13}$ Wedell K. Growing points in understanding and assessing perceptuo-motor problems. In: Gordon N, McKinlay I, eds. Helping clumsy children. Edinburgh: Churchill Livingstone. 1980:40-51.
${ }^{14}$ Michelsson K, Ylinen A, Donner M. Neurodevelopmental screening at 5 years of children who were at risk neonatally. Dev Med Child Neurol 1981;23:427-33.

15 Jaffa E. Learning disorders in young children: is neurodevelopmental screening of valuc? Public Health 1977;91:237-47.

16 Rutter M, Graham P. Yule W. A neuropsychiatric study in childhood. Novato, California: Little club clinics in Developmental Medicine nos 35 and 36. London: Heinemann, 1970.

${ }_{17}$ Mutti M, Sterling HM, Spalding NV. QNST quick neurological screening test. Academic Therapy Publications, 1978.

is The health of the school child. Report of the Chief Medical Officer of the Ministry of Education for the years 1956 and 1957. London: HMSO, 1958.

${ }^{19}$ Ounsted M, Cockburn J, Moar VA. Developmental assessment at four years: are there any differences between children who do, or do not, cooperate? Arch Dis Child 1983;58:286-9.

${ }^{20}$ Drillien C, Drummond M. Developmental screening and the child with special needs. A population study of 5000 children. Clinics in Developmental Medicine no 86. London: Heinemann, 1983.

Correspondence to Dr C R Haines, 33 Park Lane, Norwich, Norfolk NR2 3EE.

Received 9 August 1985 